\title{
SUPRA-MALLEOLAR WEDGE OSTEOTOMY OF THE TIBIA IN CHILDREN WITH MYELOMENINGOCELE
}

\author{
W. J. W. Sharrard, Sheffield, and J. Webb, Oswestry, England \\ From the Children's Hospital and the University. Department of Orthopaedics, Sheffield
}

The production and maintenance of a plantigrade foot with the maximum area of surface on the sole and heel for bearing weight is the most important aspect of the management of a foot with sensory paralysis. In children with myelomeningocele the problem is complicated by the effects of growth and the need to correct and prevent deformities arising from muscle imbalance (Sharrard 1967). In a review of the problems of foot deformity in myelomeningocele (Sharrard and Grosfield 1968) it was sometimes found that even after multiple procedures on the foot itself, residual deformity persisted at the level of the ankle joint. In this situation correction may be obtained by supra-malleolar wedge osteotomy of the tibia, a method not previously mentioned in the literature on myelomeningocele. The purpose of this paper is to describe the indications, the technique and the results of this procedure.

\section{CLINICAL MATERIAL AND INDICATIONS FOR OPERATION}

Sixteen supra-malleolar osteotomies have been performed in thirteen children, three cases being bilateral. The ages of the children ranged from four to fourteen years, with a mean of nine and a half years. There were eight boys and five girls. All had undergone previous operations for foot deformity and paralysis. Within the first two years of life equinovarus deformity had developed in nine feet, calcaneus or calcaneo-varus deformity in six feet and equinus in one foot. Soft-tissue division or tendon transfer to achieve muscle balance had

TABLE I

The Degrees of Tilt at Thirteen Ankle Joints

\begin{tabular}{|l|cc|c|c|}
\hline Degrees of tilt & 10 to 15 & 16 to 20 & 21 to 25 & Over 26 \\
\hline Valgus . & 3 & 4 & 3 & 2 \\
\hline Varus . & - & - & - & 1 \\
\hline
\end{tabular}

been performed in all cases, persistent deformity had been treated in two feet by talectomy and in six feet by Grice's extra-articular arthrodesis of the subtalar joint.

The main indications for operation were marked valgus deformity in fourteen feet (Fig. 1) and varus deformity of the hindfoot in two feet. Radiographs of the ankle before operation were available for thirteen feet and all showed abnormal valgus or varus tilting of the ankle (Fig. 2). Table I records the degrees of tilt. In some there was also abnormal mobility and opening of the joint under strain. The three feet of which radiographs were not available had had a subtalar arthrodesis previously and the clinical appearance suggested that the deformity was at ankle level.

As a result of deformity it had either become impossible for these children to wear calipers 
or the calipers were causing ulceration from pressure, on the prominent medial malleolus in valgus feet (Fig. 1) or on the lateral border of the foot in varus feet. The line of weight-bearing through the tibia no longer passed through the centre of the heel, resulting in an abnormal

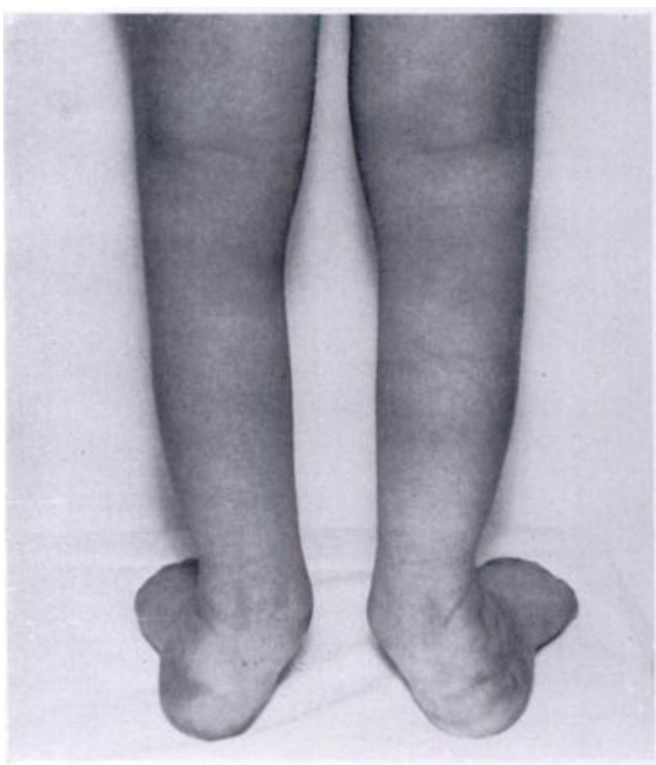

FIG. 1

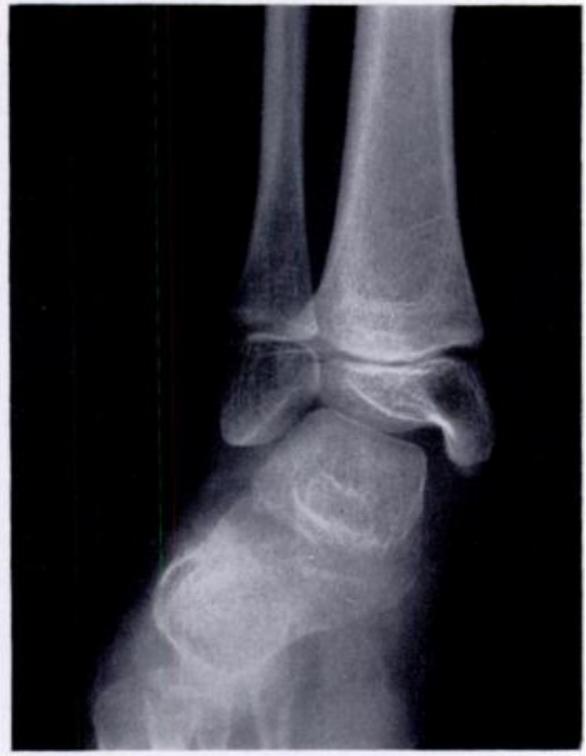

Fig. 2

Figure 1-A photograph showing the valgus appearance of both ankles before operation. An ulcer can just be seen over the left medial malleolus. Figure 2-The same patient as in Figure 1. An antero-posterior radiograph of the right ankle showing the valgus tilt before operation. Note the diminished growth of the lateral half of the tibial epiphysis due to abnormal pressure.

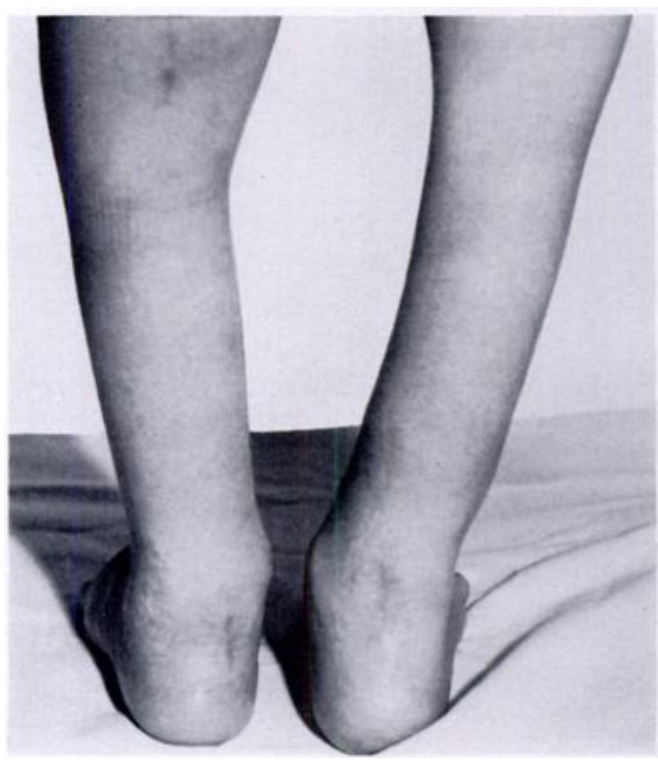

FIG. 3

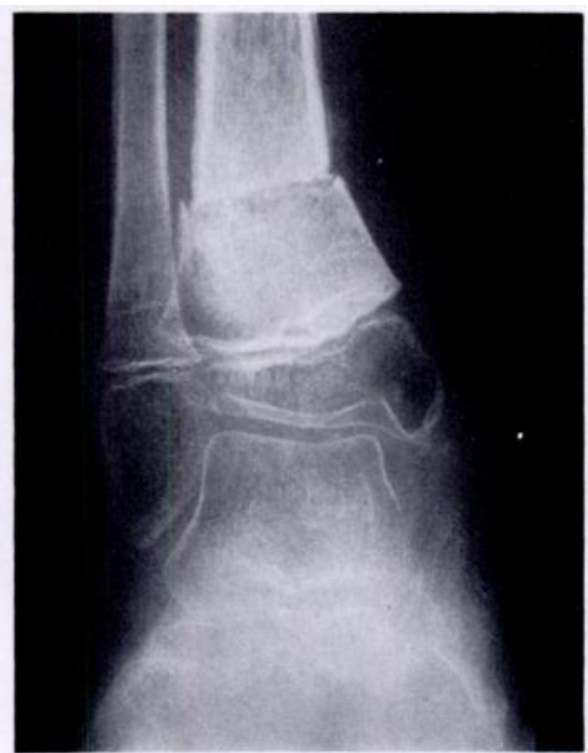

Fig. 4

Figure 3-The same patient as in Figures 1 and 2. A photograph showing the appearance of the ankles after bilateral osteotomy. The ulcer over the left medial malleolus has healed. The scars of previous operations are clearly visible. Figure 4-An antero-posterior radiograph of the right ankle after a supra-malleolar closing-wedge osteotomy, showing correction of the valgus tilt.

distribution of force at the ankle. The antero-posterior radiographs of five valgus ankles before operation suggested that abnormal pressure on the lateral half of the lower tibial epiphysis was diminishing its growth (Fig. 2). In two cases there was also medial torsion of the tibia. 


\section{OPERATION}

An anterior longitudinal incision was made over the lower third of the leg, ending at the level of the ankle joint. The deep fascia and fibres of the anterior retinaculum were divided to expose the extensor tendons and the neurovascular bundle. The lower third of the tibia was exposed by retraction of tibialis anterior and the neurovascular bundle medially and of the other tendons laterally. The periosteum over the lower third of the tibia was incised vertically down to the level of attachment of the capsule in the region of the epiphysial line and transversely at the level of osteotomy. Curved ring spikes were inserted round the bone to protect the soft tissues. A wedge of bone was then removed with an oscillating saw or an osteotome, the apex being medial in valgus feet and lateral in varus feet. The angle of the wedge was based on estimates made from radiographs taken before operation. The wedge was designed so that continuity of the cortex was maintained at the apex, allowing the gap to be closed by using a thin segment of cortical bone as a hinge. In valgus deformity it was not usually necessary to divide the fibula except in the oldest of the children, but to obtain correction of a varus deformity a piece of fibula had to be removed. Maintenance of correction did not require internal fixation, and after closure of fascia and skin a groin-to-toe plaster was applied with the foot and ankle in the corrected position, which was confirmed by radiographs. Weight-bearing was allowed two weeks later. The plaster was retained for an average of six weeks.

\section{RESULTS}

The foot was plantigrade in all patients immediately after operation (Fig. 3), and radiographs confirmed the much improved alignment of the ankle (Fig. 4). Relapse occurred in two feet soon after removal of the plaster; in both cases an opening-wedge osteotomy had been performed with interposition of a piece of fibula, a method not to be recommended. In another foot there was over-correction and a further osteotomy was needed.

In four feet there had been a clean ulcer on the inner side of the ankle at the time of operation but all four healed during the period in plaster. Two feet developed a superficial infection which healed uneventfully.

The results were reviewed eighteen months to five years after operation (mean two years). All the children except those in whom recurrence had occurred after an opening-wedge osteotomy were able to bear weight with the help of calipers, and there was no return of pressure ulceration. There was no recurrence of deformity, even in children operated upon below the age of ten.

\section{DISCUSSION}

In many foot deformities in children with myelomeningocele adequate correction can be obtained by the release of tight soft tissues and tendon transfers, but if these fail, particularly in the presence of bony deformity, operations on the bones may be needed. In general, the operations commonly used in the management of club foot or of paralytic deformity from poliomyelitis may be used in patients with myelomeningocele. Such operations include extraarticular subtalar arthrodesis (Grice 1952, 1955), talectomy (Thompson 1939, Menelaus 1971), calcaneal osteotomy (Dwyer 1959) or calcaneo-cuboid resection (Evans 1961). In this series, six Grice operations had been performed in an attempt to correct or prevent valgus deformity in feet that were essentially flail, but these operations had failed to prevent continued and sometimes progressive valgus deformity at the ankle joint. For an older child it might be thought possible to correct deformity and stabilise the ankle by means of arthrodesis of the ankle or by pantalar arthrodesis, but our experience confirms the opinion expressed by Hayes, Gross and Dow (1964) that the results are often unsatisfactory, with a risk of secondary stress fracture and tibial pseudarthrosis above the level of the ankle arthrodesis. In our hands talectomy has not proved to be a satisfactory method of correction of valgus deformity arising in the hindfoot or ankle, and in varus deformity, where it is more probably indicated, the result may be the production of a valgus ankle, as in two patients in this series. 
The results in this small series suggest that supramalleolar osteotomy is the operation of choice when there is residual valgus or varus deformity with an abnormal line of weightbearing, especially when the main deformity is at the level of the ankle. The operation has been performed mainly in children aged ten or more, lest the operation should affect growth of the lower tibial epiphysis, but even in those children in whom necessity dictated that the operation should be performed at an earlier age, there has been no evidence of disturbance of growth. Indeed, radiographs taken at follow-up have shown the restoration of normal thickness of the epiphysial nucleus and active growth at the epiphysial line. Although the mean time of follow-up is relatively short, only just two years, there has been no evidence of relapse. If recurrent deformity is going to develop after a corrective procedure on the feet of children with myelomeningocele, it usually does so within two years.

\section{SUMMARY}

1. The indications, technique and results of supra-malleolar wedge osteotomy of the tibia in the management of valgus or varus deformity of the ankle in children with myelomeningocele are described.

2. This operation should not be performed until as much correction as possible has been obtained by soft-tissue release and muscle balance has been restored by tendon transfer.

3. In sixteen feet satisfactory correction was obtained and maintained in fourteen, one of which had required revision for over-correction.

4. A closing-wedge osteotomy is recommended; the two failures occurred after opening-wedge osteotomies.

5. In the fourteen feet with satisfactory correction the complications were negligible, deformity has not recurred and epiphysial growth has been well sustained.

\section{REFERENCES}

DWYER, F. C. (1959): Osteotomy of the calcaneum for pes cavus. Journal of Bone and Joint Surgeiry, 41-B, 80-86.

Evans, D. (1961): Relapsed club foot. Journal of Bone and Joint Surgery, 43-B, 722-733.

Grice, D. S. (1952): An extra-articular arthrodesis of the subastragalar joint for correction of paralytic flat feet in children. Journal of Bone and Joint Surgery, 34-A, 927-940.

GricE, D. S. (1955): Further experience with extra-articular arthrodesis of the subtalar joint. Journal of Bone and Joint Surgery, 37-A, 246-259, 365.

Hayes, J. T., Gross, H. P., and Dow, S. (1964): Surgery for paralytic defects secondary to myelomeningocele and myelodysplasia. Journal of Bone and Joint Surgery, 46-A, 1577-1597.

MENFLAUS, M. B. (1971): Talectomy for equinovarus deformity in arthrogryposis and spina bifida. Journal of Bone and Joint Surgery, 53-B, 468-473.

Sharrard, W. J. W. (1967): Paralytic deformity in the lower limb. Journal of Bone and Joint Surgery, 49-B, $731-747$.

Sharrard, W. J. W., and Grosfield, I. (1968): The management of deformity and paralysis of the foot in myelomeningocele. Journal of Bone and Joint Surgery, 50-B, 456-465.

Thompson, T. C. (1939): Astragalectomy and the treatment of calcaneovalgus. Journal of Bone and Joint Surgery, 21, 627-647. 